\title{
When Your Students Become the Mentors
}

\author{
By Linda Bartrom-Olsen
}

A 11 of us who teach have lived through the experience of the crashing reality when we first started of how little we really knew; how limited was our ready knowledge of our discipline; how often we backed away from learner's questions, buying time so we could figure out the answers. We went into that dark tunnel of insecurity mixed with fear, and somehow came out the other side... more secure in our knowledge, and more secure about not always having the answers too. The lesson? You really really really learn a subject when you have to teach it! Oh yeah!

So how can that affect your media program? One of the greatest partnering a high school can have is with a nearby elementary trying to start a Media Program. The elementary students are awed, the high school students are honored, and you are catapulted into a "bridger" between levels. Your Principal will love this, your students will perform in ways they never knew they could, and the parents will react as though you discovered a planet.

So where do you begin? Talk to your students. Some of them may have a younger brother or sister at a nearby elementary school. Whether or not this is so, they will respond enthusiastically to showing off their skills; let them decide what they will teach, the order, the equipment they would take if the program becomes real. You will simply be amazed at how seriously they will take this. I

Once your students have worked out a lesson or two, perhaps camera work, and then filming a news show, ask your Principal for help with an introduction by email to the Principal

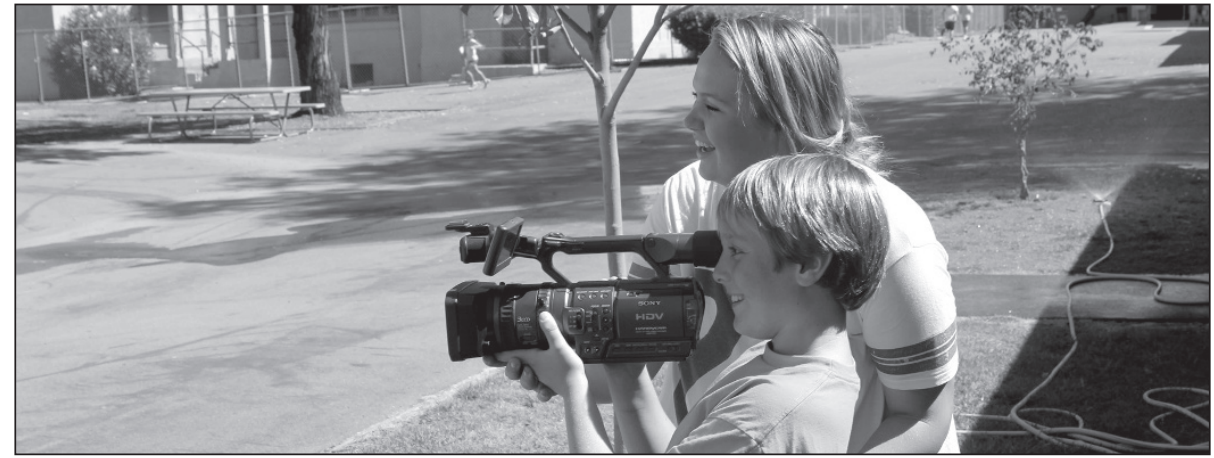

Villa Park High School, CA TV Media Student teaches camerawork operation to Villa Park Elementary Fifth Grader. Photos by Brooke Glasky and Alyssa Julian.

of a nearby elementary school with your pilot project of young Media Mentors visiting their campus. Again, you will be pleasantly surprised at the reception. Administrators meet, they know each other already, but a project like this provides a real opportunity for them to have the interactive relationship between levels that people keep telling them they should have in theory, and yet is nearly impossible when upper grades and lower grades are at different school plants. Your Principal will enthusiastically help you with an introduction; then involving a teacher at the younger school who is also interested in Media and is willing to let your young "Teachers" come in and teach a film class, is not hard to accomplish, not in this day and age. What I've experienced is actually teachers wanting the high school students to come in than I have periods to spare.

So be clear about your goals and stick to them. First semester let your students develop two lessons, make two trips, and then report on their experiences; the reports themselves are incredibly insightful. Some of the best reports I've seen in any discipline have been from students reflecting on their experiences as "teachers." Then do it again the second semester! It will become legend, you will become legend, and your program willbecome known (and I do mean known) among the parents, many of whom have learners at multiple levels. There is just no downside to this endeavor, and although it won't work when you first start your program, once you're established absolutely reach out and give this a try. I have seven students right now in Media, three on the Station Crew, two Editors and two Cast who first got interested when they were in elementary school from my students in the past who went to their elementary schools to visit!

When the "taught" become the "teachers" you will watch the skills that your learners develop reach far beyond their Media skills. The interwoven layers of age groups, the mentoring skills that develop, and the skills they hone in Media as they really (like you did) have to learn their craft because they have to teach it, will give you rewards that make the upfront investment of establishing the program well worth the outlay of your time. All things become possible when you can let go of your nestlings and turn them out into the world to become accountable for others! Good Luck! 